\title{
Philosophy and Perception of Beauty in Architecture
}

\author{
Reham Alasmar \\ Email address: \\ RHA8170771@FGS.JU.EDU.JO
}

Department of Architecture, Faculty of Engineering, The University of Jordan, Amman, Jordan

\section{To cite this article:}

Reham Alasmar. Philosophy and Perception of Beauty in Architecture. American Journal of Civil Engineering. Special Issue: Aesthetics and Perception of Beauty in Architecture. Vol. 7, No. 5, 2019, pp. 126-132. doi: 10.11648/j.ajce.20190705.12

Received: October 20, 2019; Accepted: November 12, 2019; Published: November 20, 2019

\begin{abstract}
Definitions of beauty and space are as diverse as defined by the disciplines in which it plays a fundamental role; from science and philosophy to art and architecture, each field's definition for the perception of the beauty of space is often simplified or reduced. This consequently denies us access new spaces whose definitions and perspectives, strategies and impacts on human perception of beauty of space are rarely considered in any cohesive manner. The debate, "Perception of beauty in Architecture and human perception of space". The research tries to reflect upon new understanding to the meaning of beauty in architecture and thus access new definitions and understanding to the beauty perspectives, strategies and processes of perception beauty in architecture. Some works of architecture have remarkable aesthetic value. According to certain philosophers, part of this value derives from the appearance of such constructions to fulfill the function for which they were built. The research digs through the dilemma of form follows function and argues that one way of understanding the connection between function and aesthetic value resides in the concept of functional and beauty together not the idea of function vs. beauty; the paper attempts to offer a better way of understanding it.
\end{abstract}

Keywords: Aesthetics, Perception, Beauty, Illusion

\section{Introduction}

Architecture influences the community through combining human activity with adapted site context, organized programmatic and interstitial space, and exploration of material. The dynamics of human perception, of the individual as a person and the community as a society, should influence design form and function, in terms of circulation and organization to produce sensory architecture.

Architecture is designed to attend to the needs of human activity and creates a relationship between human sensation and the building envelope to transform perception.

Throughout history there are a correlation between the human body and architecture, specifically in its relationship to human perception.

"The environment influences human beings, and this implies that the purpose of architecture transcends the definition given by early functionalism" [1].

\section{Perception}

\subsection{Ecological Nature of Perception}

The perception is the process by which an individual select, organizes and interprets stimuli into a meaningful and articulate image of the environment in which he lives.

The humans perceive surrounding through a Process:

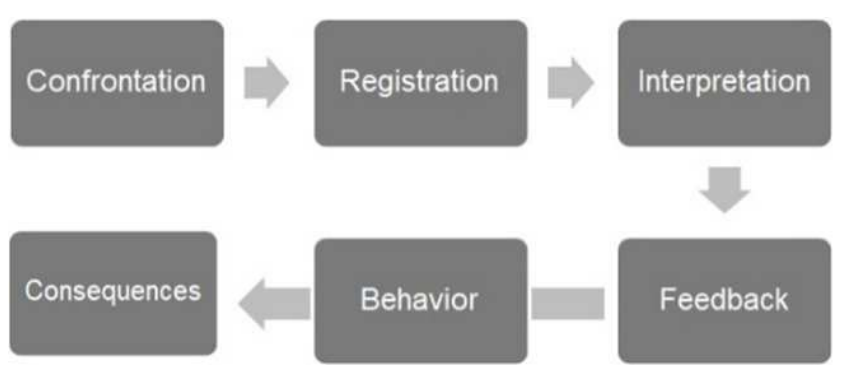

Figure 1. Process of perception.

\subsubsection{Influential Factors of Perceptual Selectivity}

The factors influencing perception of human varies between an external attention factors and internal set factors; where intensity, size, contrast, repetition and motion are an external attention factors, and learning and perception, personality and perception, and motivation and perception are an internal set factor.

Also, the perception can be influenced by the perceiver himself, the situation and the target. 


\subsubsection{Principles of Perceptual Organization}

a) Proximity rule

In mentally organizing stimuli, objects that are physically close to one another are grouped together or perceived as a unit. [2].
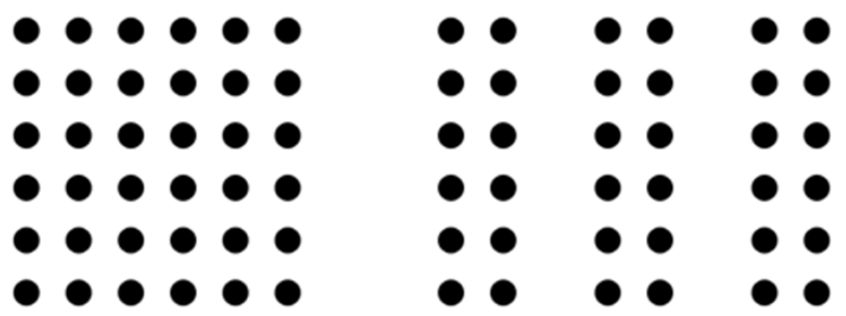

Figure 2. Proximity rule.

b) Similarity rule

In organizing stimuli, elements that appear similar in color, lightness, texture, shape, or any other quality are grouped together. [2].

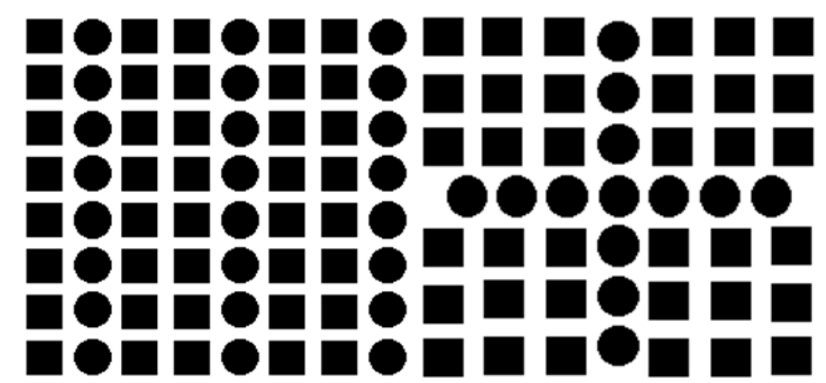

Figure 3. Similarity rule.

\section{c) Continuity rule}

The law of continuity leads us to see a line as continuing in a direction, rather than making an abrupt turn. We tend to favor smooth or continuous paths when interpreting a series of points or lines. [2].
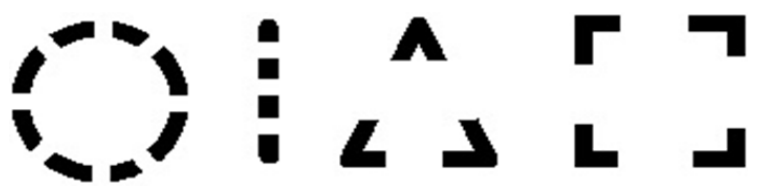

Figure 4. Continuity rule.

d) Closure rule

In organizing stimuli, the fill in any missing part or incomplete figures and see them as complete figures. [2].

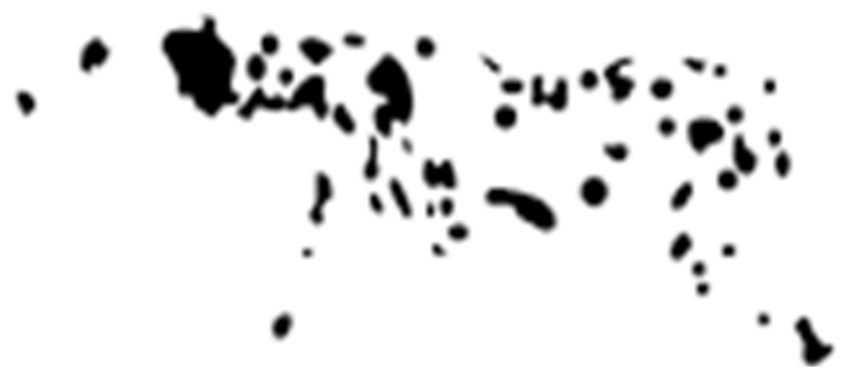

Figure 5. Closure. e) Principle of Symmetry

organizing stimulus, we tend to favor symmetrical objects or relationships.

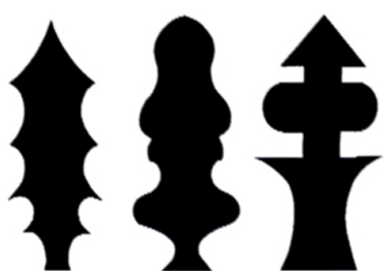

Figure 6. Principle of Symmetry.

f) Figure-ground rule

Perception does not only involve organization and grouping, it also involves distinguishing an object from its surroundings. Once an object is perceived, the area around that object becomes the background. [2].
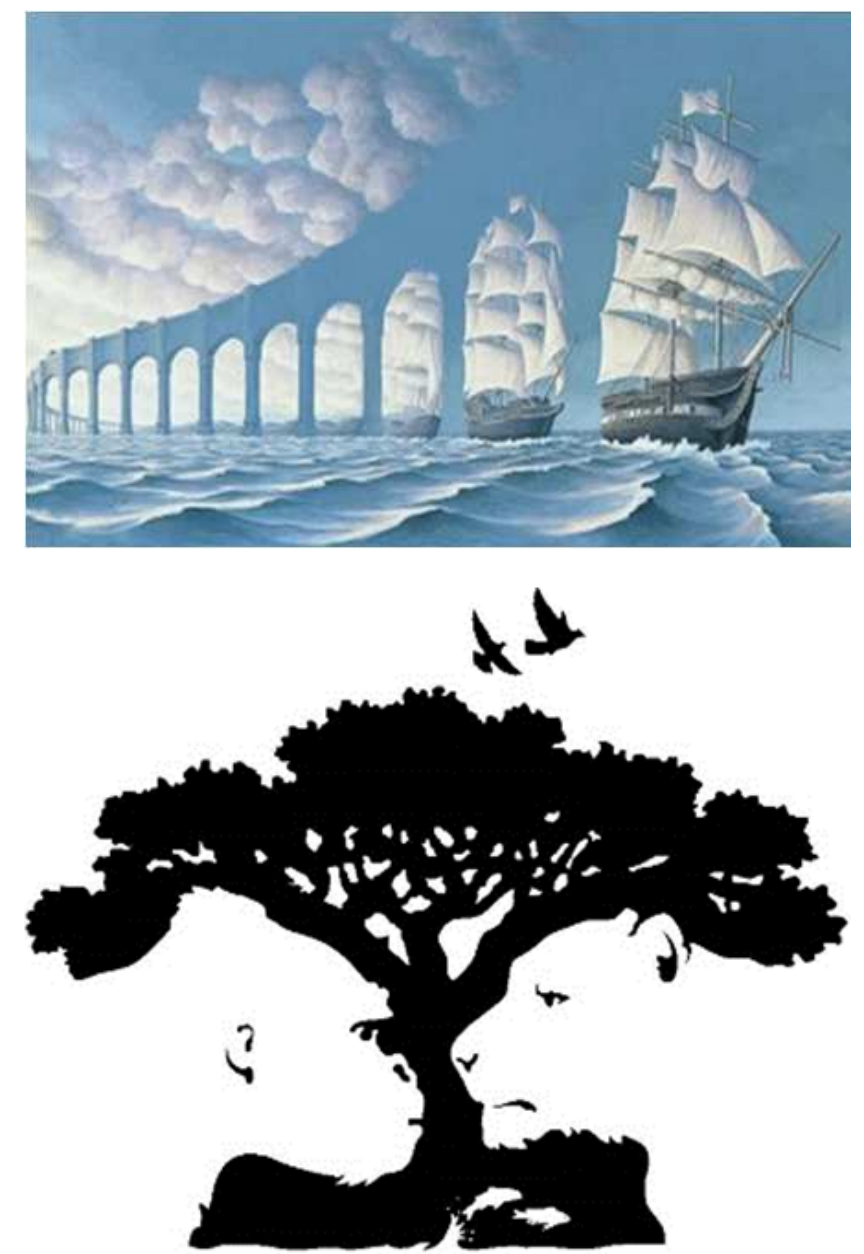

Figure 7. Figure ground rule.

\subsection{Perception Versus Sensation}

Sensation is the process of detecting, receiving, converting and transmitting information resulting from stimulation of sensory receptors. While the perception is defined as the process of selecting, identifying, organizing and interpreting sensory input into a useful and meaningful mental 
representation of the world in the light of relevant memories from past experiences. [2]

The basic function of sensation is recognition of sensory stimuli, whereas perception commonly involves interpretation and justification of the same stimuli. Our senses tell us something is out there, while our perception tells us what that something is.

Our sense matters translation of physical energy from the surrounding environment into electrical impulses to be processed by the brain. But the signals aren't understood as pure energy. The process of perception allows us to interpret these signals as objects, events, people, and situations. Without the ability to organize and interpret sensations, life would seem like a meaningless jumble of colors, shapes, and sounds.

Synesthesia literally means "mixing of senses," people with synesthesia routinely blend their sensory experience.

\subsection{Theories of Perception - Gestalt Theory}

Gestalt school practiced a series of theoretical and methodological principles that attempted to redefine the approach to principles to psychological research.

In contemporary philosophy the concept of Gestalt was first introduced by Christian von Ehrenfels (a member of the School of Brentano).

There are major theoretical principles of Gestalt psychology; Principle of Totality: The experience of perception must be considered globally through taking into account all the physical and mental aspects of the individual simultaneously because the nature of the mind demands that each element must be considered as part of a system of dynamic associations.

Principle of psychophysical isomorphism is a connection exists between conscious experience encephalic activity.

The principles of Gestalt systems:

a) Emergence: this is a description of what occurs in vision and not an explanation of what occurs. Gestalt theory does not explain how the percept of a thing emerges.

b) Reification: the generative aspect of perception, by which the experienced percept contains more explicit spatial information than the sensory stimulus on which it is on which it is based.

c) Multistability: (multistable perception) is the tendency of ambiguous perceptual experiences to pop back and of ambiguous perceptual forth unstably between two or more alternative interpretations.

d) Invariance: is the property of perception whereby Invariance simple geometrical objects are recognized independent of rotation, translation, and scale; as well as several other variations such as elastic deformations, different lighting, and different component features.

\section{Space Perception}

"Space perception is a process through which humans and other organisms become aware of the relative positions of their own bodies and objects around them. Space perception provides cues, such as depth and distance, which are important for movement and orientation to the environment." [3].

Centuries of experimental research led to a more tenable conception in which space was described in terms of three dimensions or planes:

a) Height (vertical plane).

b) Width (horizontal plane).

c) Depth (sagittal plane).

These planes all intersect at right angles, and their single axis of intersection is defined as being located within perceived three-dimensional space-that is, in the "eye" of the perceiving individual.

Our perception of space is strictly linked to spatial factors, such as composition, orientation and complexity. Furthermore light, reflection, materiality and sound play an important role for our sense of space. [4].

Our three-dimensional impression is the result of the evaluation and interpretation of the mentioned properties.

Perception of place is important. It embeds within occupant memory and influences an occupant's learned history or experience of that place. Because of perception architectural nodes and approaches are often celebrated. For example, a massive exterior can add an element of astonishment for that delicately floated interior space.

\subsection{The Visual Nature of Space}

Experiencing space is a subtle act of the human body and mind. We use our eyes to visually probe a space, making thousands of subconscious computations every second.

Way finding, orientation, direction, etc. The lens of our eye, with a $22 \mathrm{~mm}$ focal length allows us to experience perspective space in a consistent and readable way. [5].

Space is self-evident, but the way we perceive it is not. Our brain has built in mechanism that allows visual inputs to be recorded and processed, outputting information almost simultaneously that we then act upon. The processing of visual information sometimes triggers cognitive loopholes. These loopholes are known as optical illusions.

Illusions trick our brain's visual mechanics and have limiting relevance on three dimensional spatial effects.

\subsection{Spatial vs. Visual}

Our experience of space is largely determined by our biopsychology.

In 2014 research from Edvard and May-Britt Moser won the Nobel Prize for Physiology and medicine. A series of geometric grid-like cells inside the brain of rat are discovered, these cells function much like a GPS system, allowing us to spatially map and navigate space in an objective way. Our movement through space is recorded by 
our brain using acceleration, movement and speed. This means that for each spatial situation, there is an objective recording and reading occurring within our brains. [6].

Supplementing the spatial recording in the entorhinal cortex is a recording of visual properties in the hippocampus. This deal with recording colors, textures and recalling memories that have occurred in visually similar spaces. A complex series of information exchange occurs between these two distinct portions of our brain, allowing us to write, recall and place memories. This duality help explains why memory is so closely tied to place.

If every person can write spatial memories or draw it as diagrams, then it is not our language or culture that commands how we react to a space, but rather a combination of objective human nature and hyperindividualistic responses. The spatiality of various architectural typologies is powerful in the way that they are able to affect the biopsychology of an individual in a moment and time of life.

\subsection{Spatial Types}

Symmetrical spaces create the effect of monumentality. Asymmetrical spaces are less monumental by their very nature, as they allow for more variation and dynamisms and do not have such a rigid hierarchy. The spatial effects of scale differ as to whether it is the absolute scale of an object or space or relative to that of another. Absolute scale is best used when the user can experience a large object and slowly approach it, fully understanding its massiveness. Entering narrow passageways before being led into a spread-out void is a compelling spatial effect.

The spatial effect of bearing is especially effective because it is a common to all cultures and all architectural movements worldwide.

The more reduced this structural relationship is, the more elementary it becomes.

Porosity is the measure of voids within a solid of composition. It exists purely in three dimensions and is spatially significant because it creates spaces that are varied and interconnected. It blurs the firm boundaries between space and architectural elements.

Porous objects are varied in their scale and composition, characteristics that put the user in the forefront of the space or object.

There are numerous spatial effects that have been used compelling throughout the history of architecture. It is our role as architects to evaluate each project considering site; client and function and to decide which types of spaces we want to create.

The vessels that architects are designing contain space, and that powerful spaces have a primacy that goes far beyond that of provocative shapes.

Architecture is one of the only professions that create space and it should embrace the opportunity to better understand the spatial qualities we are designing.

\section{Beauty}

There is no particular definition of beauty; it is defined as a basic pleasure. And can be something intrinsic to object (color, form, and other qualities) or simply the pleasure an object evokes.

\subsection{Aesthetics}

The term aesthetics is derived from the Greek word Aisthanesthai which refers to perceive cognition. Means the things that are recognizable. Aesthetic experience as a particular case of integration with aesthetic theme for no other reason than to continue interacting with it as a result of what we feel of pleasure, discovery, satisfaction or concern with the impact of this interaction.

Distance is the hallmark of the most important steps during artistic creation and it can be useful in describing what is generally called artistic mood.

The 20th century's leading physicists agree that beauty is the primary yardstick of practical truth. The aesthetic preference is a complex process that includes comparisons, distinctions and choices between available aesthetic alternatives. This aesthetic preference is expressed through special aesthetic judgments issued by the individual.

\subsection{Theories of Beauty in Architecture}

\subsubsection{Golden Ratio}

Ratio of the sum of the quantities to the larger quantity is equal to the ratio of the larger quantity to the smaller one.

Ancient Greek mathematicians first studied it because of its frequent appearance in geometry. The ratio is approximately 1.6180. "Extreme and mean ratio" was the principal term used from the 3 rd century BC until about the 18th century. [7].

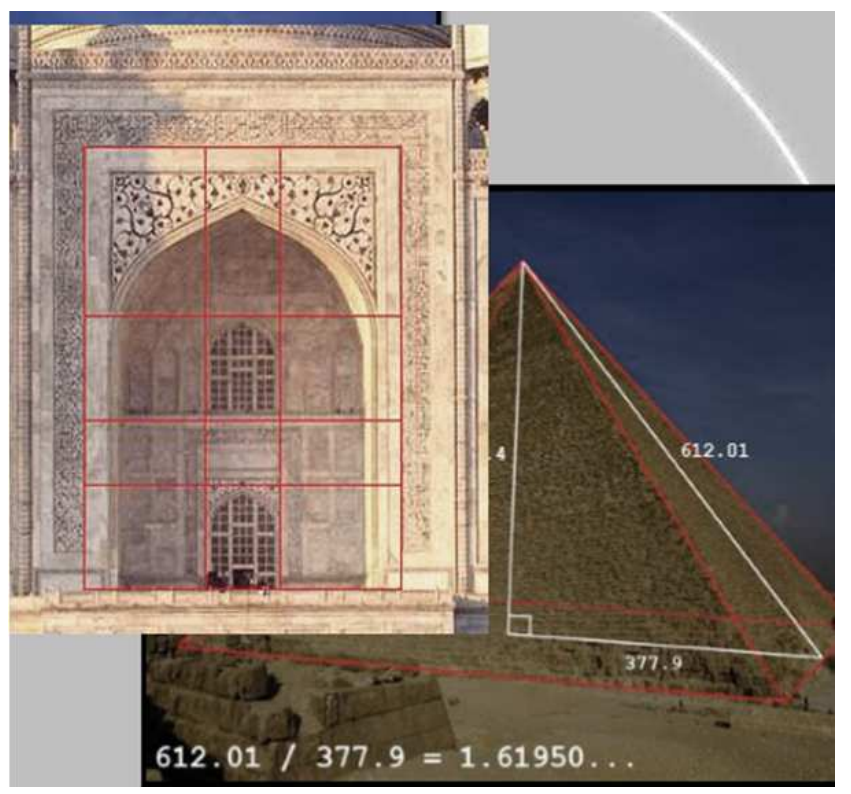

Figure 8. Golden ratio in architecture. 


\subsubsection{Vitruvius's Theories of Beauty}

Vitruvius believed that an architect should focus on three central themes when preparing a design for a building: firmitas (strength), utilitas (functionality), and venustas (beauty). [8].

Venustas theory is a complicated one. Vitruvius thought that a timeless concept of beauty could be learnt from the 'truth of nature', that nature's designs were based on universal laws of proportion and symmetry. He thought that the body's proportions could be used as a model of natural proportional perfection.

Vitruvius showed that the 'ideal' human body formfitting exactly into a square and a circle, and thus illustrated the link that existed between perfect geometric forms and the perfect body as he believed.

It followed, an architect's designs must refer to the unquestionable precision of the body's symmetry and proportions.

\section{Perception of Beauty}

The question of whether architecture matters or not is something that you see running right through the history of religion, politics, economics, art and so much more.

There is a very basic thought of whether the space that we are in creates an influence, either negative or positive, that we should take very seriously, and if so, we should respond to that challenge.

The problem with unsuccessful architects is that what they do hangs around for a very long time. In other words, architecture is a serious business, and I do think that it impacts on our state of mind. So, if you become sensitized to architecture and its good and bad moments, you will be unhappy a lot of the time, because most of the world has gone wrong. Architects who worked aesthetically in architecture become what the 19th Century started to get to know as an 'aesthete'. The most famous aesthete in the 19th Century was of course Oscar Wilde, who famously said that "the wrong kind of wallpaper could upset him far worse than a death in the family". [9].

A beautiful building was understood to be a classical building. It is one that basically borrows from the architecture of the Greeks and the Romans. So, whereas in 1730 , the choice of beautiful building has been classicism.

When sensitive architectural critics saw these buildings, they were disgusted, and it seemed to them an indicator of everything that could start to go wrong when choice entered the field of architecture, when people could not distinguish if something is beautiful or not.

Now, the answer, when it eventually starts to emerge, starts to come from an odd direction - not from architects, but from engineers.

You look at what a building should do, and that determines what it should look like.

So, there should be no more arguments about aesthetics, no more agonized discussions about what sort of arch to put in. You would look at what the programme is, you would look at what the function is, and you determine what a building should look like in that way.

This is a very unusual assumption. For thousands of years, architects had seen their job as of course having certain functional, mechanical directions - keeping out the rain, etc. - but they also saw themselves as decorators and as artists.

Modernist architects rejected all of this, where the French architect Le Corbusier, who came at the beginning of the 20th Century and work against decoration and aesthetic motivations of traditional architects.

Le Corbusier talked about efficiency, but he was just interested in things looking nice, and if it was a choice of it really working or looking like it worked, he always wanted things to look like they worked. The language of science is used by the modern movement in architecture to justify its choices. [10].

Building performance is used by architects traditionally to ground their decisions in arguments. Where in recent years we are seeing that architects are beginning to discover that the reason of doing things in such way is its nice image.

we are slowly seeing a return in architecture of an awareness that buildings should be communicating and that a good building is not just an efficient building, it is also one that talks to us of the right sort of things.

Now, the interesting thing is that when we say that we find something beautiful, we are not just saying that we like the way it looks.

If you scratch below the surface, really what we are saying is we like the outlook on life that this object is suggesting to us.

So, if you think this building is beautiful, One way of describing that beauty is to describe simply the physical object, but another way of doing it is to say, for instance, that there is some sort of harmonious feeling that is coming from it, and that you want to live there, and you could quite easily describe the qualities of the life that you might have if you lived around it.

"If we have settled that aspect of things, we are still left with all sorts of conundrums, one of which is that, if we accept that beauty is important, and if we accept that beauty emanates from the personality of objects." [7].

So, it is almost as though, when decorating spaces, what we try to do is to surround ourselves by objects which capture a spirit, as I say, that we're attracted to but don't fully possess.

There is something elusive about the things that we find beautiful.

Deconstructivism is a movement of the middle to late twentieth century that focused on the importance of language. Essentially, the deconstructivism believed that an individual's perception was predetermined by their thoughts, knowledge, and cultural background. This movement became the base for postmodern architecture, and it adopted that language and symbolism were essential building blocks of architecture. [11]. 
The contemporary view, which taken by philosophers and psychologists in the past two decades, is that perception and language are different things, and perception does not occur immediately. Rather, through the process of perception people first perceive, then think, and thirdly conceptualize or express thoughts.

The architectural postmodernism used symbolism to give meaning to their architectural concepts. Its language-based architecture was a series of symbolic objects as intellectual exercise in building. The problem is that the architecture offered little in terms of objective spatial qualities. The contemporary view allows for the design and experience of space without symbolism and without needing a metaphor, the primacy of space becomes much more important. This creates a sense where architects do not need to reference something outside of architecture. Architecture after that can be made up of simple, proto architectural elements and objects.

\section{Illusion and Perception in Architecture}

Impressions of space and structure can be controlled to create illusions of symmetry, scale, distance, 'weightlessness', and even 'dematerialization' of the visual planes by altering 'proportions and appearance'. Ruskin notes that "all architecture proposes an effect on the human mind, not merely a service to the human frame" [12].

\subsection{Illusion of Scale}

The illusion of scale was a technique utilized in the Library of Celsus, in the Roman city (Asia Minor). In a limited area amid existing buildings, the building appears to be enormous. The twenty-one meters wide marble-paved courtyard leads to the two-story gallery, which rests at the top of nine wide marble steps. Pairs of columns support pediments located on two levels; the central columns create the illusion of enlarged space between the columns. Along with the inclined edges of the podiums, the size of the central doorway strengthens the illusion by being perceived taller and wider than other adjacent.

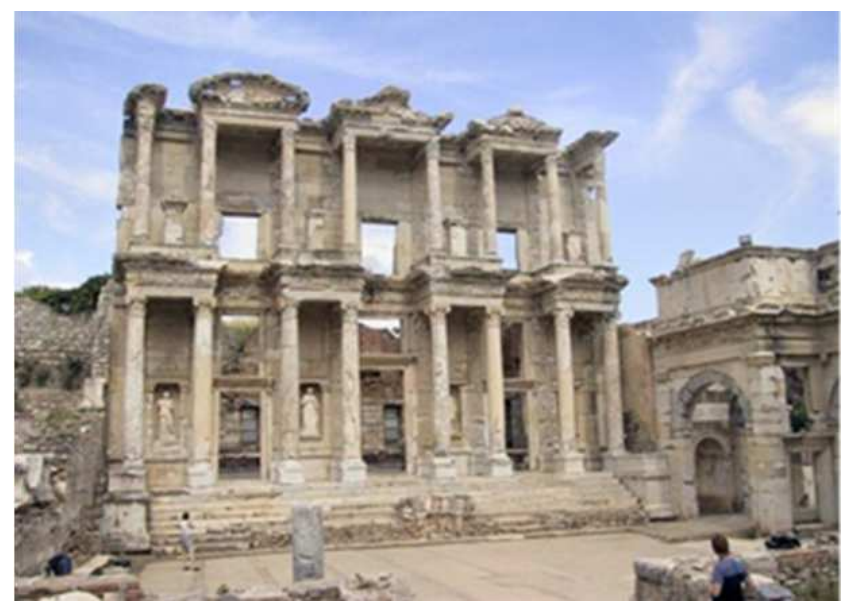

Figure 9. Library of Celsus.

\subsection{Illusion of Weightlessness}

Architectural objects can look suspended in space in spite of their massive structure. In Istanbul, Turkey, the church of Hagia Sophia, built by Isadora's and Anthemion, circa 535, is a Byzantine church, later used as an Ottoman mosque, and is currently serving as a museum. Its massive dome appears light on the lower structure above the huge volume, though hidden structural piers to provide required support. [13].

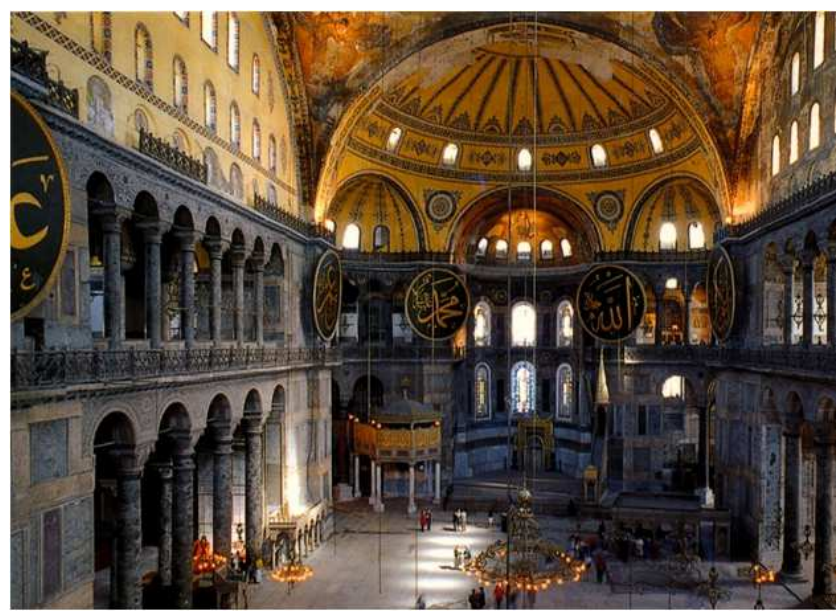

Figure 10. Hagia Sophia.

Gothic churches present a similar effect, where monumental "external "flying buttresses", were used to sustain the weight of the roof, while being hidden from viewers inside, and producing the effect of lightness. The Coutances Cathedral is considered a classic example.

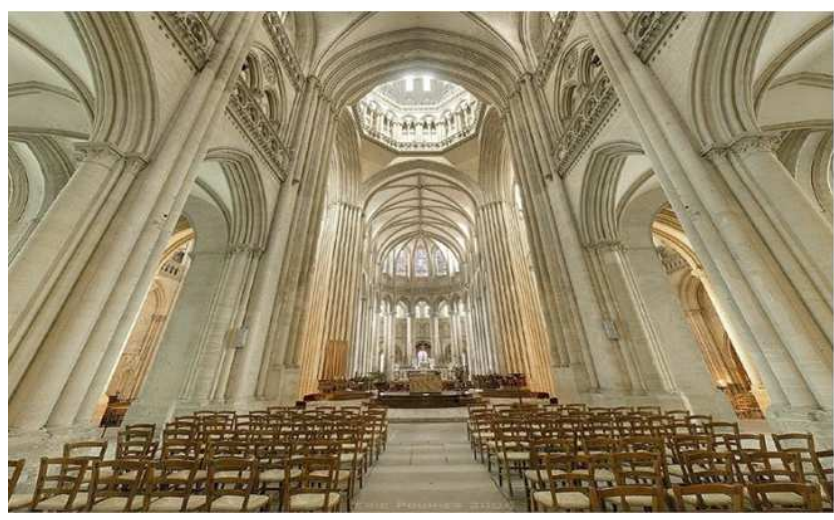

Figure 11. The Cathedral at Coutances.

\subsection{Illusion of Plane Dematerialization}

Mediterranean and Eastern cultures have exhibited 'patterned optical illusions' on floors of tiles or woodwork, which seem to deconstruct the flat plane of floor and design another illusive one. Examples have been found in a number of countries including Andalusia, Morocco, Japan, China, India, Persia, and Italy. [14]. 


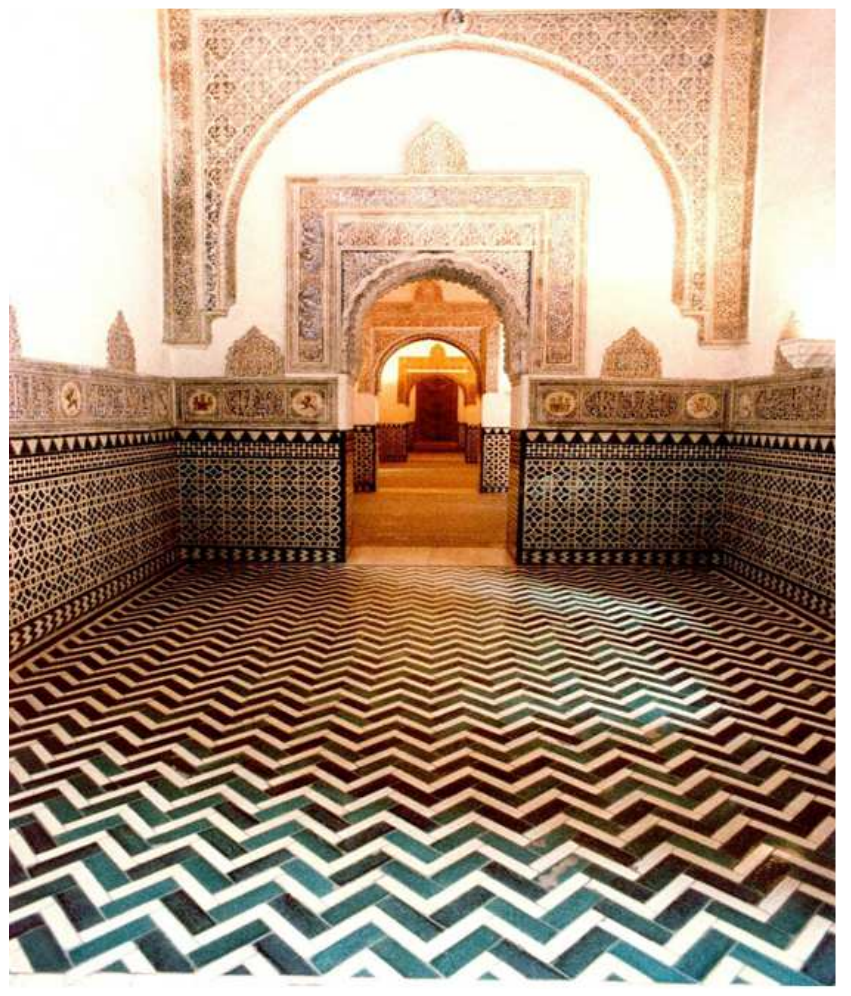

Figure 12. Mosaic Tile patterned floor at Alcazar, Seville (Spain).

\subsection{Correctional Illusion}

The satisfaction of eye occurs only when the appearance is satisfactory. There have been instances through history where the mistakes of pure vision have been overcome by correctional design techniques. [15].

Since what is true appears false and things seem different from what they are, in representing them we must add or subtract. While if it is an architectural facade, this involves deconstruct lines or replace it by curves, thickening and disposing selective parts. Figure 13 illustrates columns that swell in the middle, corner columns swell, and architraves lean forward.

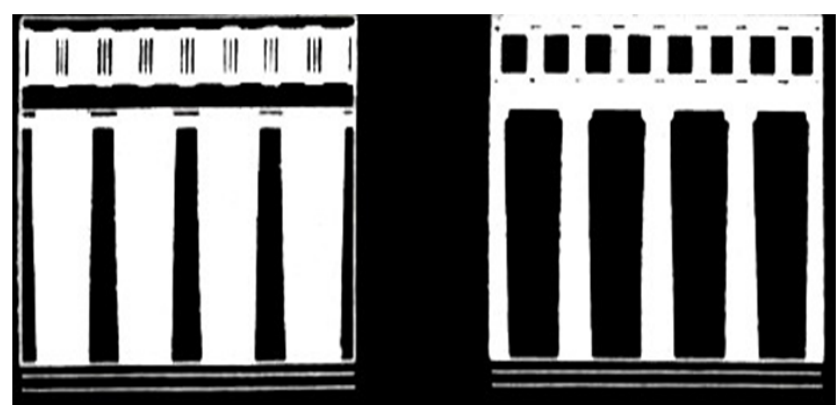

Figure 13. Irradiation in architecture.

Optical illusion can play a subtle role in everyday living even affecting how architecture is constructed. Parthenon's outer columns looks thicker at the top and rectilinear inward at a slant so that from certain viewpoints the building appears taller and straighter.

Optical illusion that can change your perception: a huge impact on the size, proportion and mood of a space.

\section{Acknowledgements}

I submit my heartiest gratitude to my parents for their keen interest, encouragement and great help through working on this research paper.

\section{References}

[1] Theory of Phenomenology: Analyzing Substance, Application, and Influence. (2012). Arch 630: Theory and Context.

[2] perception, S. a. $(2019,10)$. Introductory psychology. Retrieved from Lumenlearning: https://courses.lumenlearning.com/suny-hccc-ss-1511/chapter/gestalt-principles-of-perception/

[3] West, P. Y. (2017). Space perception. Encyclopaedia britannica.

[4] Coyle, A. (2002). Managing prisons in a time of change. London: International Centre for Prison Studies.

[5] Cladera, A. (2017). The Ultimate Photography Guide to Depth of Field (DoF). Photopills.

[6] Hodges, F. M. (2003). The promised planet: Alliances and struggles of the gerontocracy in American television science fiction of the 1960s.

[7] Akhtaruzzaman, M., \& Shafie, A. A. (2011). Geometrical Substantiation of Phi, the Golden Ratio and the Baroque of Nature, Architecture, Design and Engineering. International Journal of Arts.

[8] Kruft, H. (1994). A history of architectural theory from Vitruvius to the present. London.

[9] Botton, A. D. (2008). The architecture of happiness. New York: Vintage books.

[10] Ozkan, S. (2001). Development of Thinking and Theory in Architecture. CSBE.

[11] TMD Studio, (2017). The visual nature of space, Spatial perception and architecture.

[12] 1, A. d. (2009). Delight, the Function of Ornament, An Exploration of its Relevance. The Netherlands.

[13] Allen, W. (2013). Hagia Sophia, Istanbul. Arts and Humanities.

[14] Devine, P, G., \& Sherman. (1992). Intuitive versus rational judgment and the role of stereotyping in the human condition; kirk or spock, psychological inquiry.

[15] Anthony J. Reilly. (1998). Three approaches to organizational learning. Jsmith library body. 